\title{
CLEAR CELL MYOEPITHELIAL CARCINOMA OF OROPHARYNX : A CASE REPORT
}

Dr. Adil S. A. K, Dr. G. Nataraju, Dr. Ravi Kumar T.

1. Assistant Professor, Department of Pathology, Mysore Medical College \& Research Institute, Mysore.

2. Professor, Department of Pathology, Mysore Medical College \& Research Institute, Mysore.

3. Post Graduate Student, Department of Pathology, Mysore Medical College \& Research Institute, Mysore.

\section{CORRESPONDING AUTHOR}

Dr. S.A.K. Adil,

\# 259, $5^{\text {th }}$ Main,

Bannimantap, 'C' Layout, Mysore,

E-mail: saka291@yahoo.co.in,

Ph: 09019691259.

ABSTRACT: Myoepitheliomas are rare neoplasms. We present a case of clear cell myoepithelial carcinoma arising from submucosal minor salivary glands of oropharynx.The significance of this lesion is that it is a recent entity 1,2 and it shares morphological similarities with many neoplasms that pose a challenge in the diagnosis.

It has to be distinguished from benign myoepitheliomas and neoplasms with predominantly clear cells like mucoepidermoid carcinoma, clear cell carcinoma, acinic cell carcinoma, metastatic renal cell carcinoma etc. Imaging studies were unremarkable and immunohistochemistry was crucial for the diagnosis.

KEYWORDS: Myoepithelial Carcinoma- clear cell variant, minor salivary gland, Oropharynx.

INTRODUCTION: Primary myoepithelial tumors in oral cavity are rare neoplasms. ${ }^{1}$ Clinically, they commonly present as painless mass.

Clear cell myoepithelial carcinoma is very rare and it is recently considered as a separate tumour entity ${ }^{2}$.Awareness of this lesion is important as the differential diagnosis of this lesion can be extensive. These neoplasms diagnostically require evidence of myoepithelial differentiation.

In this report, we present a rare case of clear cell myoepithelial carcinoma arising from minor salivary glands in oropharynx.

CASE HISTORY: A 75-year-old male, presented with difficulty in swallowing not associated with pain since one month. No history of known malignant diseases was present. Clinical examination revealed a proliferative growth of $4 \times 3 \mathrm{~cm}$ in the oropharynx on the posterior pharyngeal wall.X-ray chest and ultrasonographic study of abdomen was found to be normal.

PATHOLOGICAL FINDINGS: Grossly, the specimen consisted of an irregular brown bit of tissue measuring $1 \mathrm{x} 0.5 \mathrm{cms}$. Cut section was grey white. The entire tissue was taken for processing. Microscopically the sections showed a neoplasm comprising of monomorphic population of clear cells arranged in solid nodules separated by fibrous septa. These cells contain abundant amount of cytoplasm and bland nucleus, which was central to eccentrically placed.Occasional cells showed granular eosinophilic cytoplasm.The neoplasm showed invasion into the adjacent stroma.Necrosis was not evident and mitotic figures were rare. Immunohistochemical studies 
confirmed the nature of the tumor. The cells showed immunopositivity for cytokeratins, p63, S100 and caldesmon.

DISCUSSION: Myoepithelial carcinoma has been recently recognised as a separate tumour entity ${ }^{1,2}$. Clear cell variant of myoepithelial carcinoma is comparatively much rarer than other variants and only few cases have been reported in literature.

It has a wide age distribution ranging from $14-86 y$ rs $^{1}$ and is usually encountered in the parotid gland, nasopharynx, paranasal sinus, nasal cavity and breast. Clinically, they usually present as painless mass.

The neoplasm exhibits a wide spectrum of cytomorphologic features and the tumour cells often are spindled, stellate, epithelioid, plasmacytoid (hyaline), or, occasionally, vacuolated With signet ring like appearance.1,5.

Clear cell tumours are a challenge to diagnosis as variety of lesions have similar morphological features. Myoepithelial carcinoma can be distinguished from benign myoepithelial tumours by invasion of the neoplasm into the adjacent stroma ${ }^{1}$, which was evident in our case.

The neoplasm showed monomorphic population of clear cells similar to clear cell-rich salivary gland tumors which include mucoepidermoid carcinoma, pleomorphic adenoma, acinic cell carcinoma, clear cell carcinoma.

Mucoepidermoid carcinoma consists of mucin containing cells, squamous cells, and intermediate cells. Pleomorphic adenoma is identified by the distinct chondro/fibromyxoid stroma and acinic cell carcinoma and clear cell carcinoma stain negatively for myoepithelial markers.

Imaging studies were undertaken to exclude any renal mass.

Immunohistochemistry plays a critical role in the diagnosis of this tumour.

Cytokeratin expression indicated the epithelial nature of this neoplasm and the myoepithelial markers p63, caldesmon and S-100 which were positive in our case,confirmed the diagnosis as myopithelial carcinoma.

Literature search reveals the therapy options for this lesion are conservative excision with a margin of uninvolved tissue or radiation and chemotherapy which also has resulted in a significant shrinkage of the tumour. $5,6,7$.

CONCLUSION: Clear cell myoepithelial carcinoma can share morphological features with various clear cell entities and pathologists should be aware of this lesion.

New immunohistochemical markers for myoepithelial cells which are crucial for accurate diagnoses of this neoplasm are p63, and caldesmon along with S-100. 
fig1 Malignant cells with clear cytoplasm and bland nucleus(H \& E,X 40)

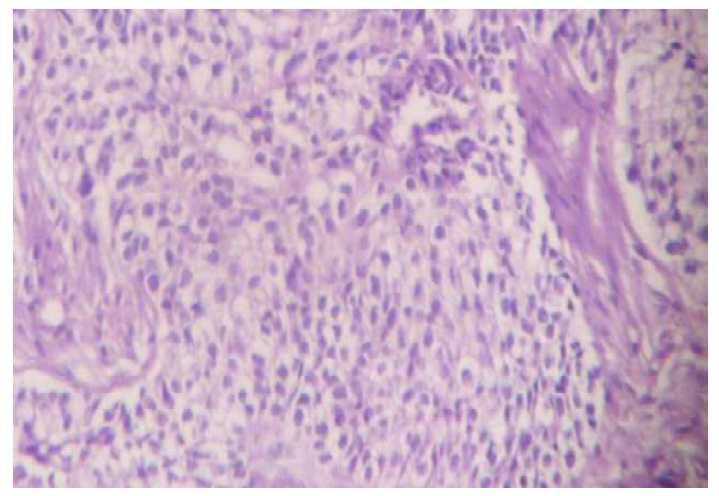

Fig 3- Tumor cells showing cytoplasmic positivity for cytokeratin immunostain(X 20)

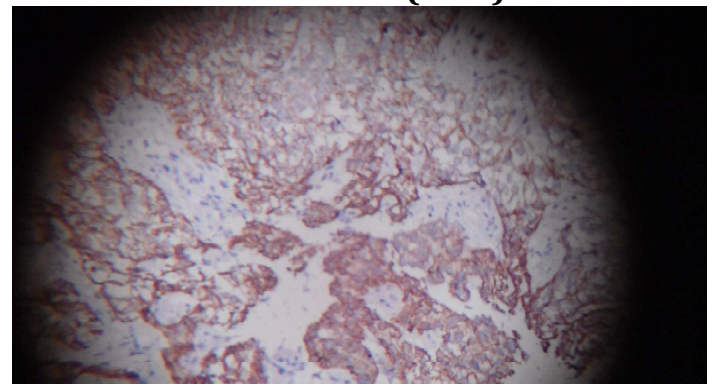

5- Tumor cells showing cytoplasmic positivity for caldesmon immunostain( $X$ 10)

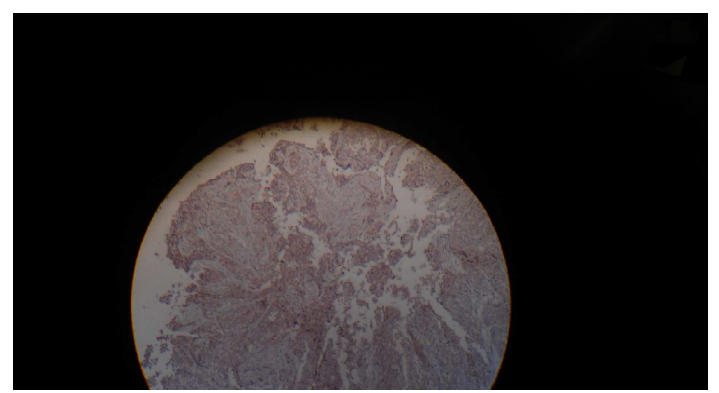

Fig 2- Malignant cells infiltrating into stroma(H \& E,X 20)

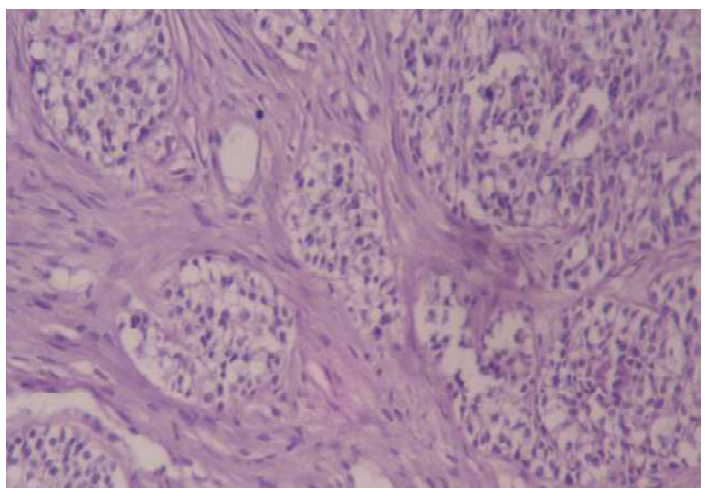

Fig 4- Tumor cells showing nuclear positivity for p63 immunostain(X 20)

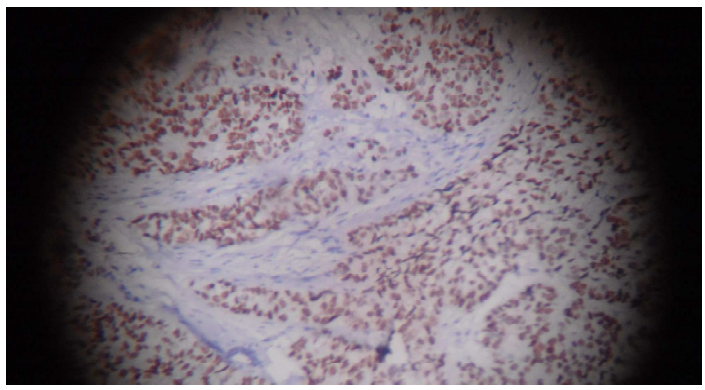

6- Tumor cells showing variable nuclear and cytoplasmic light intensity stain in myoepithelial cells for S- 100 (X 40)

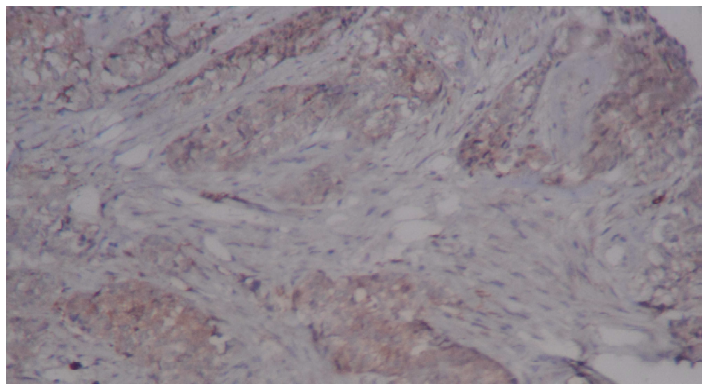

\section{REFERENCES:}

I. Barnes L, Eveson J. W, Reichart P, and Sidransky D. World Health Organization Classification of Tumours. Pathology and Genetics of Head and Neck Tumours, IARC Press, Lyon, France, 2005.p242-243

II. Wang B,Brandwein M, Gordon R, Robinson R, Urken M, Zarbo R J. Primary Salivary Clear Cell Tumors-A Diagnostic Approach. Arch Pathol Lab Med. 2002; 
Vol126 (6):676-685

III. Savera A T, Sloman A, Huvos A G, Klimstra D S. Myoepithelial carcinoma of the salivary glands: a clinicopathologic study of 25 cases. Am J Surg Pathol. 2000; vol 24(6):761-74.

IV. Fletcher.C.D.M. Diagnostic pathology of tumors, 2ndedition, Vol.1, London; Churchill Livingstone, 2000.p250-251

V. Rosai.J.Rosai and Ackerman's Surgical Pathology.9thedition.Vol 1 India;Elsevier, 2011.p888-89

VI. Ren J,Liu Z,Liu X,Li Y,Zhang X, Li Z,Yang Y,Yang Y,Chen Y,Jiang S Primary myoepithelial carcinoma of palate. World J Surg Oncol.2011; 9:104 doi10.1186/1477-7819-9-104.

VII. Mills S.E,Carter.D,Greenson.K.J,Oberman.A.H, Reutar.V,Stoler.M.H.Sternbergs Diagnostic Surgical Pathology.Vol 2.U.S.A.Lippincott Williams \&Wilkins.2004.pp 943-944. 